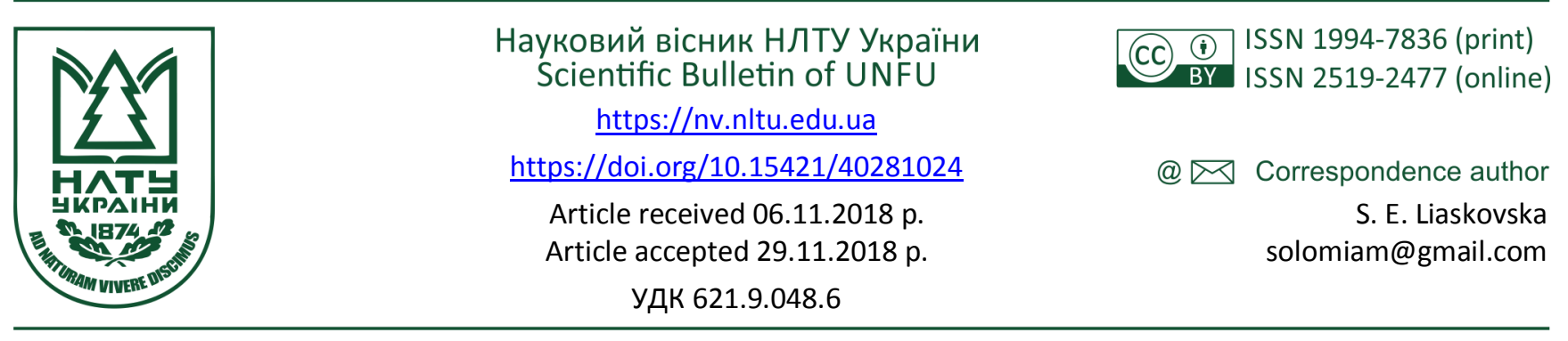

О. Т. Велика, С. Є. Лясковська, В. І. Тодавчич

Національний університет "Львівська політехніка", м. Львів, Украӥна

\title{
ОПТИМІЗАЦІЯ ЕТАПІВ МОДЕЛЮВАННЯ ТА ВІЗУАЛІЗАЦІЇ ВИРОБІВ МАШИНОБУДУВАННЯ
}

Проаналізовано етапи моделювання та візуалізації виробів машинобудування. Створено тривимірну модель деталі типу "Диск" та досліджено особливості ії рендерінгу. Описано процес створення максимально наближеного до реалістичного зображення моделі деталі машинобудування, яку побудовано у системі автоматизованого проектування Solid Works в додаткy Photo View 360. Складено факторну математичну модель Mv, аналізом якої встановлено, що якість комп'ютерного моделювання та візуалізації просторових деталей прямо залежить від взаємозв'язків визначальних функціональних параметрів, а саме множини вхідних даних, які необхідні для розроблення технічного завдання проекту, графічної складової, що містить результати каркасного та 3D-моделювання, компоненти часу опрацювання даних для подальшої візуалізації тощо. Використовуючи розроблену факторну математичну модель, а також основу рендерінгу, розв'язок рівняння, що описує розповсюдження світла у тривимірній сцені, складено схему послідовності створення рендеру об'єктів машинобудування. У пропонованій схемі подано основні етапи обробки зображення, а також представлені методи зафарбовування примітив. Розглянуто приклади рендерінгу деталі типу "Диск" із використанням різних ефектів, зокрема: 3 відлитої міді, з оцинкованого металу, 3 великого пластику. Окреслено переваги використання різних ефектів для візуалізації об'єктів у галузі машинобудування.

Ключові слова: CAD-система; рендерінг; реалістична 3D-модель; візуалізація об'єктів; SolidWorks; додаток Photo View 360.

Вступ. Підготовка конструкторської документації на виробництві для підвищення результативності демонстрації розробок замовникові чи користувачеві здійснюється за допомогою сучасних інформаційних технологій. Актуальним постає завдання представити вироби в найбільш конкурентоспроможному вигляді, щоб залучити максимальну кількість клієнтів. Сучасний ринок CAD-систем дає змогу обрати ефективні засоби для візуалізації розроблених моделей устаткування, обладнання, деталей тощо. Тому візуалізація - це один із найважливіших етапів комп'ютерної графіки, за допомогою якого розробник отримує завершене зображення виробу чи деталі.

Для отримання реалістичної моделі виробу, деталі чи технологічного устаткування, графічне зображення, a саме 3D-модель виробу, проходить певний шлях оброблення. Завершальним етапом графічного оброблення $€$ рендерінг. Використання функцій прикладних програм дає змогу одержувати реалістичне зображення розробленого виробу. Застосування відповідного модуля підвищує якість проектування моделей та об'єктів. Існує безліч програм - рендерів, зокрема: Artlantis Studio, Autodesk 3ds Max, V-Ray, Maxwell Render, FryRender, IndigoRenderer, LuxRender, КОМПАС-3Д (додаток Artisan Rendering), SolidWorks (додаток Photo View 360)

та інші. Ці середовища забезпечують виконання різних типів операцій та часто використовують їх у різних сферах - від графіки сучасних відеоігор до візуалізації та презентації виробів у машинобудуванні.

Постановка проблеми. Рендерінг (англ. rendering "візуалізація") - етап у комп'ютерній графіці, який забезпечує обробку 3D-моделі виробу за допомогою спеціалізованих програмних середовищ. Модуль, який виконує рендерінг, називають рендером (render) або рендерером (renderer). Тому актуальне завдання полягає в аналізі етапів перетворення звичайної 3D-моделі до максимально реалістичної, використовуючи при цьому різні методи системи автоматизованого проектування. Це допомагає покращити якість зображення та отримати значно більше уявлення про модель, оцінити зовнішній вигляд та деталізувати (підібрати косметичні) параметри розробки, налагодити ефективну ланку спілкування між замовником та розробником, тобто налаштувати зворотній зв'язок.

Аналіз останніх досліджень і публікацій. Проблему покращення візуалізації зокрема рендерінгу та оптимізації конструкції деталей на підставі методу скінченних елементів розглянуто у працях (humskyi, 2013; Liaskovska \& Boiko, 2012; Kaliutov, 2015). Першим етапом у створенні алгоритмів побудови реалістичних моделей

Інформація про авторів:

Велика Оксана Тарасівна, канд. техн. наук, доцент, кафедра проектування та експлуатації машин. Email: veloks@ukr.net

Лясковска Соломия Евгеньевна, канд. техн. наук, доцент, кафедра проектування та експлуатації машин.

Email: Solomiam@gmail.com

Тодавчич Вячеслав Іванович, студент, кафедра проектування та експлуатації машин. Email: viacheslavtodavchych@gmail.com

Цитування за ДСтУ: Велика О. Т., Лясковська С. Є., Тодавчич В. І. Оптимізація етапів моделювання та візуалізації виробів машинобудування. Науковий вісник НЛТУ України. 2018, т. 28, № 10. С. 124-128.

Citation APA: Velyka, O. T., Liaskovska, S. E., \& Todavchych, V. I. (2018). Optimization of the stages of modeling and visualization of machine building products. Scientific Bulletin of UNFU, 28(10), 124-128. https://doi.org/10.15421/40281024 
деталей став аналіз різних етапів рендерінгу (Ilina \& Bizhko, 2016; Romaniuk, 2007), а також особливостей застосування можливостей 3D-рендерінгу для порівняння моделей готового виробу, під час розроблення якого відбулася місце зміна візуальних параметрів та виробу, який залишався косметично усталений.

Метою дослідження є вивчення особливостей впливу взаємозв'язків параметрів на якість рендерінгу моделей деталей і процес одержання їх зображень.

Викладення основного матеріалу дослідження. Комп'ютерне моделювання та візуалізація просторових деталей прямо залежить від взаємозв'язків параметрів, а саме: геометрії досліджуваного об'єкта, компонентів часу, організаційних чинників, та можна його описати факторною математичною моделлю (Romaniuk, 2007):

$$
M v=(V d, G r, T i, \text { Ren, Org }),
$$

де: $V d-$ множина вхідних даних, які необхідні для розроблення технічного завдання проекту; $G r$ - графічна складова, що містить результати каркасного та $3 D$-моделювання; $T i$ - компонента часу опрацювання даних для подальшої візуалізації; Ren - етап рендерінгу, що об'єднує дані про модель та їі опис і вибрані програми рендери; Org - сукупність організаційних чинників, які впливають на процес візуалізації моделей деталей машинобудування, містить інформацію про зворотний зв'язок між розробником та замовником, який здійснюється від початкового етапу до заключного етапу створення рендерінгу виробу.

Взаємозв'язки цих компонентів забезпечують якісний процес опрацювання даних для одержання графічного зображення i, як кінцевий результат рендермоделі. Процес рендерінгу означає візуалізацію, формування моделей деталей, а модель отримують внаслідок моделювання, опис якої здійснюється за допомогою певної мови програмування або у вигляді структур, списків, масивів тощо. Опис моделі містить геометричні дані у вигляді тривимірних координат точок моделі, параметри здійснених змін, трансформацій, тобто переміщення, масштабування, поворотів тощо, координати параметрів освітлення, властивостей матеріалів (текстура, колір). Опрацьовуючи всі фактичні дані, програма-рендер виконує візуалізацію моделі. Теоретичною основою рендерінгу є розв'язок рівняння, що описує розповсюдження світла у тривимірній сцені (Kaliutov, 2015):

$$
\begin{gathered}
L_{0}(x, \omega, \lambda, t)=L_{e}(x, \omega, \lambda, t)+ \\
+\int_{\Omega} f_{r}\left(x, \omega^{\prime}, \omega, \lambda, t\right) L_{i}\left(x, \omega^{\prime}, \omega, \lambda, t\right)\left(-\omega^{\prime} \cdot n\right) d \omega^{\prime},
\end{gathered}
$$

де: $\lambda$ - довжина хвилі світла; $t$ - час; $L_{0}(x, \omega, \lambda, t)-$ кількість випромінювання заданої хвилі довжини; $L_{e}(x, \omega, \lambda, t)-\quad$ світло, що випромінюється; $\int_{\Omega} f_{r}\left(x, \omega^{\prime}, \omega, \lambda, t\right) L_{i}\left(x, \omega^{\prime}, \omega, \lambda, t\right)\left(-\omega^{\prime} \cdot n\right) d \omega^{\prime},-$ інтеграл по напівсфері вхідних напрямків; $L_{r}\left(x, \omega^{\prime}, \lambda, t\right)$ - двонаправлена функція розподілу відбиття, тобто кількість випромінювання відбитого світла від $\omega^{\prime}$ до $\omega$ в точці $x$ з напрямку $\omega^{\prime}$ за час $t ;\left(-\omega^{\prime} \cdot n\right)-$ поглинання вхідного випромінювання за заданим кутом.

Функція $f_{r} \epsilon$ важливою у теорії рендерінгу і має назвy bidirectional reflectance distribution function (BRDF), тобто двонаправлена функція розподілу відбиття. BRDF описує оптичні властивості відбиття поверхні та $\epsilon$ абстрактною математичною одиницею. Тобто для опису рівняння рендерінгу можна використати освітлення в точці, яке складається 3 енергії променів, що утворюються від джерел світла, а також від енергії променів, які відбиваються. Потрібно враховувати також властивості поверхні, геометрію об'єкта тощо.

3 урахуванням (1), процес створення максимально наближеного до реалістичного зображення розглянемо для моделі деталі машинобудування, яку побудовано у системі автоматизованого проектування Solid Works у додатку Photo View 360. У цьому випадку продукт Solid Works має такі переваги: забезпечує моделювання виробів (деталей), роботу над конструкторською документацією, формує промисловий дизайн, виконує розрахунок моделей на міцність, стійкість, моделює процес механооброблення тощо. Проектування виробів будь-якого ступеня складності з урахуванням специфіки виготовлення деталі з використанням Solid Works відрізняється від інших CAD-систем простотою процесу побудови. Використовуючи розроблену факторну математичну модель (1), рівняння (2), що описує розповсюдження світла у тривимірній сцені, складено схему послідовності створення рендеру об'єктів машинобудування, що містить взаємозв'язки між етапами та методами, які застосовують у досліджуваному процесі (рис. 1).

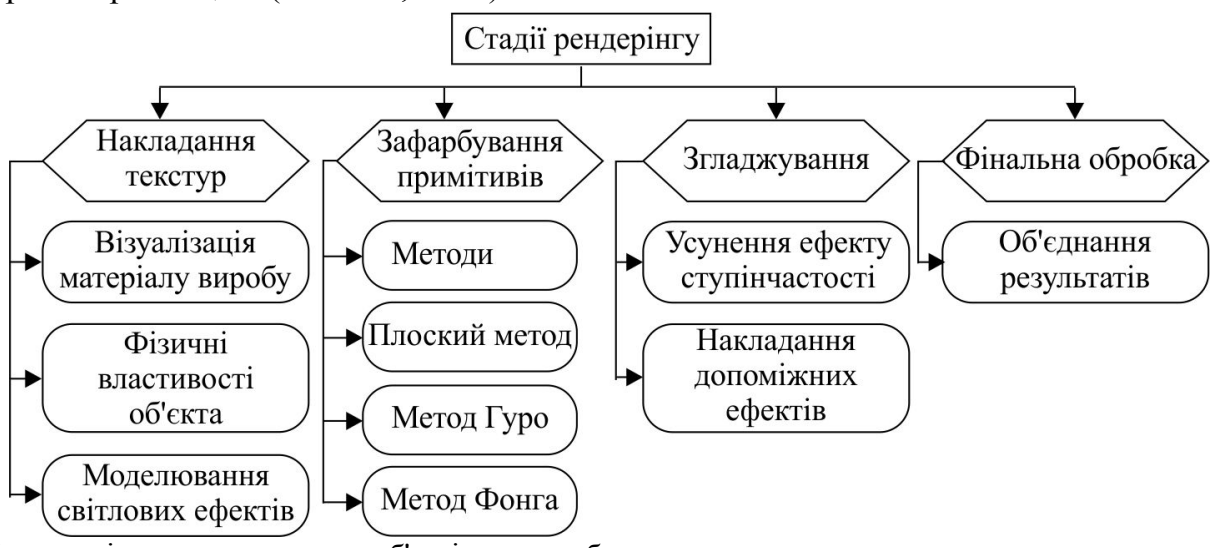

Рис. 1. Схема послідовності створення рендеру об'єктів машинобудування

Стадії рендерінгу можна розділити на такі етапи: накладання текстур, зафарбування примітивів, згладжування ліній та поверхонь, одержання фінального оброблення. На кожному з перерахованих етапів програмоюрендером здійснюють функції, а саме: етап накладання текстур поділяється на візуалізацію матеріалу виробу, фізичні властивості об'єкта, моделювання світлових ефектів. Зафарбовування примітивів містить методи, за допомогою яких здійснюється зміна кольору. Ми виділили такі методи: плоский метод, метод Гуро, метод 
Фонга. Згладжування розділимо на такі кроки: усунення ефекту ступінчастості та накладання допоміжних ефектів. Фінальною обробкою $є$ об'єднання всіх результатів моделі об'єкта машинобудування.

Розглянемо для прикладу процес розроблення моделей виробів типу "Диск", модель якої підлягає візуальній обробці (рис. 2).

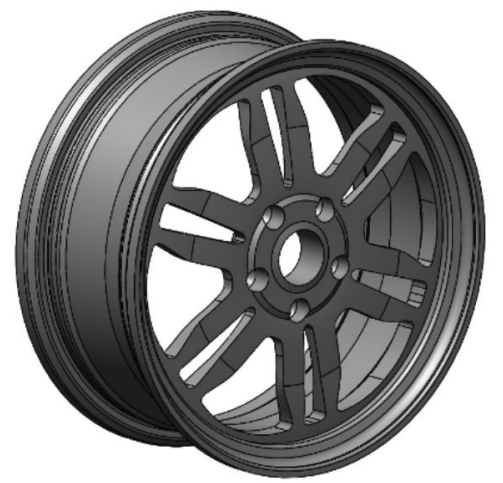

Рис. 2. Модель деталі "Диск" до візуального оброблення

Перший етап дослідження відповідно до (1), полягає в аналізі способів розроблення рендеру моделі деталі в додатку Photo View 360 (рис. 3).

$$
\begin{aligned}
& \text { D'S SOLIDWORKS Файл правка вид вставка Инструменты Окно справка, }
\end{aligned}
$$

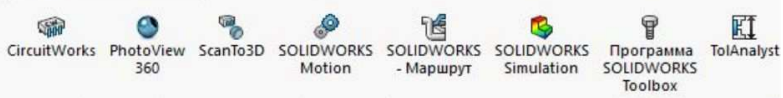

\begin{tabular}{|l|l|l|l|l|} 
Элементы & Эскиз Анализировать & Dim`реrt Добавления SOLIDWORKS SOLIDWORKS MBD
\end{tabular}

Рис. 3. Верхня панель додатку Photo View 360

Для докладного аналізу процесу рендерінгу окреслимо такі кроки використання додатку Photo View 360.

Вибір типу матеріалу досліджуваної деталі (рис. 4). У верхньому правому кутку вибираємо "Внешние виды, сцены и надписи" $\rightarrow$ "Внешние виды (color)" $\rightarrow$ "Meтал" $\rightarrow$ "Хромированная плита".

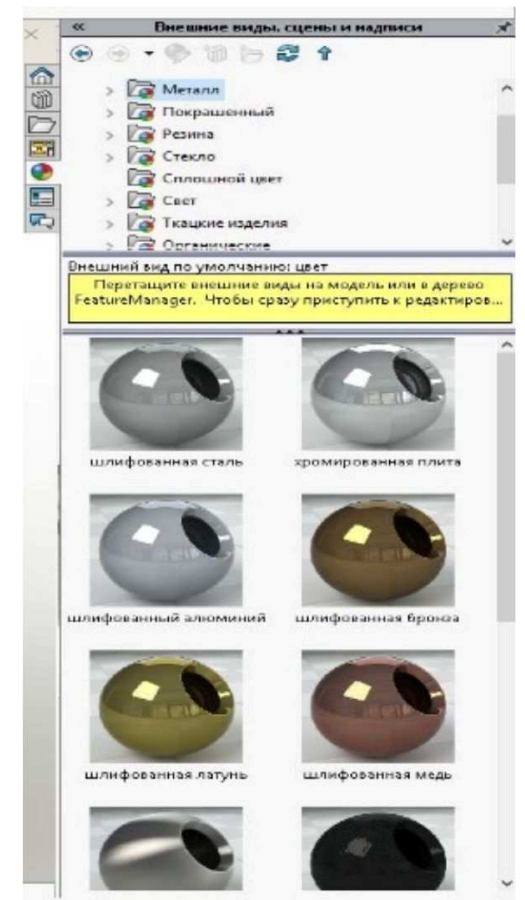

Рис. 4. Вибір типу матеріалу в додатку Photo View 360

Наступним етапом за допомогою параметра "Просмотр настроек" обираємо всі параметри відображення моделі (рис. 5).

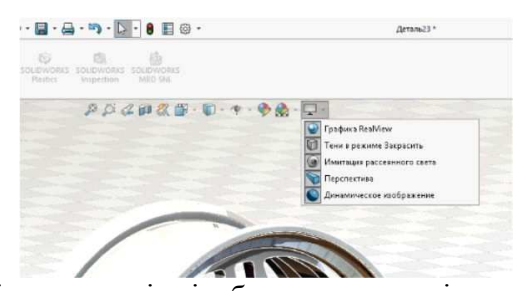

Рис. 5. Вибір параметрів відображення моделі деталі

Обираємо сцени, які найкраще демонструють вироби машинобудування, а саме: "Внешние виды, сиены $u$ надписи" $\rightarrow$ "Сценьл". Можливо додавати емблему, логотип виробника, напис тощо (рис. 6).

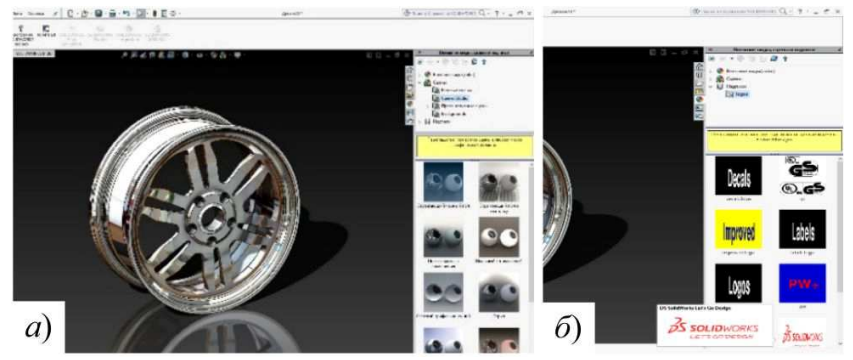

Рис. 6. Вибір сцени та емблеми, логотипу виробника

За допомогою вставки "Инструменты отрисовки" регулюємо параметри освітлення, фону, тіней на підлозі, величину відображення тощо (рис. 7).

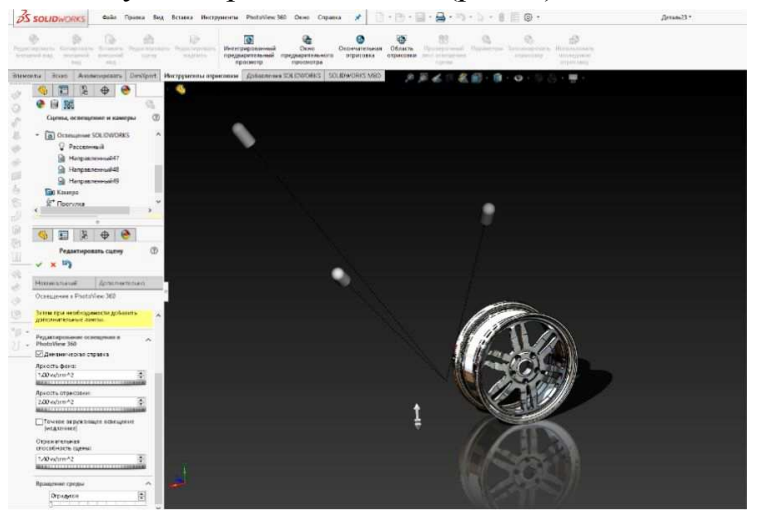

Рис. 7. Вибір параметрів освітлення, фону, тіней, величини відображення

Для попереднього перегляду результату рендерінгу використовуємо команду "Интегрированный предварительный просмотр" та "Окно предварительного просмотра". За їхньою допомогою будуємо модель деталі із залученням зі заданих користувачем параметрів деталі (рис. 8).

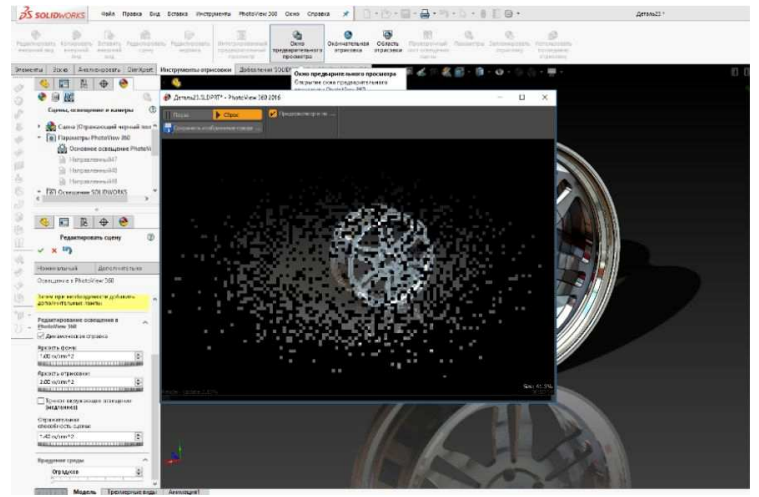

Рис. 8. Команда перегляду рендеру моделі

Під час регулювання параметрів можна отримати достатню кількість результатів рендерингу, а також візуалізацію, близьку до реального відображення деталі чи зборки. На рис. 9 подано приклади візуалізації із змі- 
ною параметрів, що відповідають за відтворення ефектів, що демонструють види матеріалів. На рис. 9, $a$ представлено деталь "Диск" у хромованому вигляді. На рис. 9,б зображено деталь "Диск" мідно-дзеркального кольору.
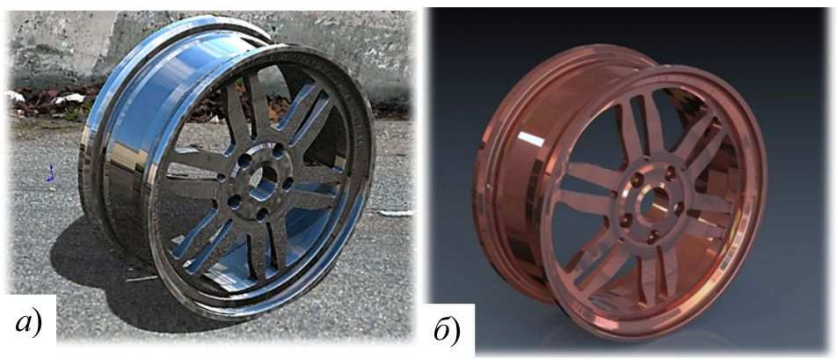

Pис. 9. Деталь "Диск" після оброблення в Photo View 360: а) хромована деталь; б) деталь мідно-дзеркального кольору

Створенням фонового середовища моделі, додаванням матеріалу, тіньових ефектів від поверхні, сцени, змінюється уявлення про деталь. Оброблення деталей у Photo View 360 дає можливість отримати чітке уявлення про продукт на ринку, а виробникові - якісно та повноцінно презентувати свою продукцію. На рис. 10 зображено рендери моделі деталі "Диск", які вдало передають форму поверхні деталі, матеріал, рельєф виробу.

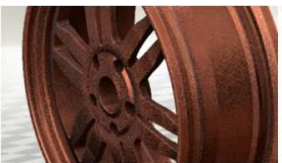

a)

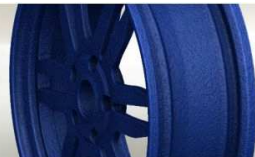

б)

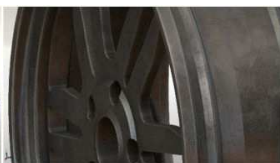

6)
Рис. 10. Рендери деталі "Диск": a) із відлитої міді; б) з оцинкованого металу; в) із великого пластику

Окреслимо переваги використання рендерінгу для оброблення 3D-моделей деталей:

- значно вища презентабельність виробу;

- можливість оцінювання якості моделі деталі в процесі складання зборки;

- краще уявлення про зовнішній вигляд деталі;

- відсутність потреби виготовлення пробних примірників деталі для презентації;

- швидке вирішення проектних завдань.

Ефективне використання рендерінгу можливе з урахуванням двох чинників: достатній рівень підготовки розробника і сучасне технічне забезпечення для комфортної роботи та попереднього перегляду результату рендерінгу.
Висновки. Візуальне представлення рендеру моделі деталі надає унікальну можливість зрозуміти іiі конструкцію. Для складних деталей та громіздких зборок додатково потрібне глибоке розуміння схем і креслень: якісний рендерінг дає змогу усім зацікавленим сторонам зрозуміти, що презентовано на зображенні. Це зможе здійснити розробник, замовник та майбутній користувач.

Проведено аналіз процесу рендерінгу у CAD-системi Solid Works (додаток Photo View 360) на прикладі моделі деталі "Диск". Створено рендери розробленої моделі, які передають форму поверхні деталі, матеріал, рельєф виробу тощо. Складено факторну математичну модель для аналізу взаємозв'язків між різними етапами проектування виробу, зокрема описано залежність параметрів для комп'ютерного моделювання деталі та подальшої візуалізація виробу. Використано рівняння рендерінгу, що описує розповсюдження світла у тривимірній сцені, на підставі якого складено схему послідовності створення рендеру об'єктів машинобудування. У пропонованій схемі подано основні етапи обробки зображення, а також представлено методи зафарбовування примітивів. Результати дослідження дають змогу систематизувати послідовність етапів рендерінгу у CAD-системах для графічного оброблення та візуалізації моделей, зокрема в галузі машинобудування.

\section{Перелік використаних джерел}

Hrytsiuk, Yu. I., \& Nemova, E. A. (2018). Management Features Process of Developing Software Requirements. Scientific Bulletin of UNFU, 28(8), 161-169. https://doi.org/10.15421/40280832

Ilina, I. V., \& Bizhko, O. V. (2016). Analiz osoblyvostei vizualizatsii tryvymirnykh obiektiv. Systemy upravlinnia, navihatsii ta zviazku, 2(38), 88-92. [In Ukrainian].

Kaliutov, A. V. (2015). Vvedenie v fotorealisticheskuiu grafiku. St. Petersburg: Politekhnika, 118 p. [In Russian].

Liaskovska, S. Ye., \& Boiko, M. V. (2012). Renderynh yak efektyvnyi zasib vizualizatsii modelei vyrobiv u seredovyshchi CATIA V5. Optymizatsiia vyrobnychykh protsesiv $i$ tekhnichnyi kontrol u mashynobuduvanni, 746, 18-20. [In Ukrainian].

Romaniuk, O. N. (2007). Prohramno-aparatna realizatsiia renderinhu tryvymirnykh zobrazhen v systemakh kompiuternoi hrafiky. Pratsi Odeskoho politekhnichnoho universytetu, 2(28), 158-162. Retrieved from: http://coremission.net. [In Ukrainian].

Shumskyi, V. (2013). GPU y Cloud Renderynh. LAP Lambert Academic Publishing, 108 p. [In Ukrainian].

О. Т. Велыка, С. Е. Лясковска, В. И. Тодавчич Национальный университет "Львовская политехника", г. Львов, Украина

\section{ОПТИМИЗАЦИЯ ЭТАПОВ МОДЕЛИРОВАНИЯ И ВИЗУАЛИЗАЦИИ ИЗДЕЛИЙ}

МАШИНОСТРОЕНИЯ

Проанализированы этапы моделирования и визуализации изделий машиностроения. Создана трехмерная модель детали типа "Диск", исследованы особенности ее рендеринга. Описан процесс создания максимально приближенного к реалистическому изображению модели детали машиностроения, построенной в системе автоматизированного проектирования SolidWorks в приложении Photo View 360. Составлена факторная математическая модель Mv, анализом которой установлено, что качество компьютерного моделирования и визуализации пространственных деталей напрямую зависит от взаимосвязей определяющих функциональных параметров, а именно, множества входных данных, необходимых для разработки технического задания проекта, графической составляющей, содержащей результаты каркасного и 3D-моделирования, компоненты времени обработки данных для дальнейшей визуализации. Используя разработанную факторную математическую модель, а также основу рендеринга, решение уравнения, описывающего распространение света в трехмерной сцене, составлена схема последовательности создания рендера объектов машиностроения. Рассмотрены примеры рендеринга детали типа "Диск" с использованием различных эффектов, в частности, отлитой меди, из оцинкованного металла, из крупного пластика. Определено ряд преимуществ использования различных эффектов для визуализации объектов в области машиностроения.

Ключевые слова: CAD система; рендеринг; реалистичная 3D-модель; визуализация объектов; SolidWorks; приложение Photo View 360. 


\section{OPTIMIZATION OF THE STAGES OF MODELING AND VISUALIZATION}

OF MACHINE BUILDING PRODUCTS

Rendering is a stage in computer graphics, which provides the processing of 3D models with the help of specialized software environments. The actual task is to analyze the stages of conversion of the usual 3D model to the most realistic, using the various methods of the automated design system. Rendering allows improving the quality of the image and get a much more idea of the model, evaluate the appearance and detail development parameters, it also provides an effective link between the customer and the developer, that is, sets up feedback. The stages of modeling and visualization of machine-building products are analyzed. The threedimensional model of the "Disk" is created and special features of its rendering are researched. The process of creating a model of a machine-building component that is as close as possible to the realistic image of the model in SolidWorks Photo View 360 application is described. We have defined the factor mathematical model Mv. The analysis of this model has proved that the quality of computer simulation and visualization of details directly depends on the interrelationships certain functional parameters of the interrelationships, the set of input data necessary for the development of the technical task of the project, the graphic component containing the result you frame and 3D models time data processing components for further visualization. Using the developed factor mathematical model, as well as the basis of reediting, the solution of the equation describing the propagation of light in a threedimensional scene, the scheme of the sequence of creating a render of machine-building objects is compiled. The examples of rendering details of the Disk type are considered using various effects, in particular, from cast copper, galvanized metal, and large plastics. A number of advantages of using various effects for visualization of object models in the field of machine-building are described.

Keywords: CAD system; rendering; realistic 3D model; visualization of objects; SolidWorks; Photo View 360 application. 